\title{
Proton MR spectroscopy of human pancreas allografts
}

\author{
Jan Weis ${ }^{1}\left[\right.$ D $\cdot$ Håkan Ahlström ${ }^{2} \cdot$ Olle Korsgren $^{3}$
}

Received: 10 December 2018 / Revised: 21 January 2019 / Accepted: 22 January 2019 / Published online: 1 April 2019 (c) The Author(s) 2019

\begin{abstract}
Objective To estimate pancreas graft relaxation times and concentrations of total fat, and the intracellular lipids of nonadipose pancreatic cells (NAPC) using proton $\left({ }^{1} \mathrm{H}\right)$ magnetic resonance spectroscopy (MRS) during cold preservation.

Materials and methods Grafts from 11 human donors were investigated. Each pancreas was perfused in situ with histidinetryptophan-ketoglutarate (HTK) or with University of Wisconsin solution and placed into a transport container. Temperature of the grafts was maintained at $4 \pm 2{ }^{\circ} \mathrm{C}$ during transport to our hospital and MR scanning. A $1.5 \mathrm{~T}$ clinical scanner was used for the measurements. Single-voxel PRESS spectra were acquired using transmit-receiver head coil.

Results Relaxation times were measured for lipid $\left(-\mathrm{CH}_{2}-\right)_{\mathrm{n}}\left(T_{1}, 287 \pm 60 \mathrm{~ms} ; T_{2}, 27 \pm 4 \mathrm{~ms}\right)$, and tissue water $\left(T_{1}, 670 \pm 69 \mathrm{~ms}\right.$; $T_{2}, 77 \pm 17 \mathrm{~ms}$ ). Average total fat, and intracellular lipids of NAPC concentrations were 79.2 \pm 100.8 (range 2.4-304.4), and $2.9 \pm 1.2 \mathrm{mmol} / \mathrm{kg} \mathrm{ww}$, respectively.

Conclusion We have shown that ${ }^{1} \mathrm{H}$-MRS is a useful tool for the estimation of pancreas graft lipid concentrations. Total pancreatic fat and especially content of intracellular lipids of NAPC are valuable measures for inspection of graft quality prior to transplantation or islet of Langerhans isolation.
\end{abstract}

Keywords ${ }^{1} \mathrm{H}$-MRS $\cdot$ Pancreas graft $\cdot$ Relaxation times $\cdot$ Total fat $\cdot$ Intracellular fat

\section{Introduction}

The pancreas plays an important role in the synthesis and secretion of digestive enzymes and metabolism-regulating hormones. The majority of pancreas volume contains exocrine glands that are dedicated to producing enzymes which help to digest proteins, fats, and carbohydrates (sugars). Approximately $2 \%$ of the pancreas mass consists of different hormone-producing endocrine cells which clump together into small clusters called islets of Langerhans. The hormones made by alpha and beta cells in the islets produce glucagon and insulin, respectively. These two hormones regulate the sugar levels in the blood and cells.

Jan Weis

jan.weis@ radiol.uu.se

1 Department of Medical Physics, Uppsala University Hospital, 75185 Uppsala, Sweden

2 Department of Radiology, Uppsala University Hospital, Uppsala, Sweden

3 Rudbeck Laboratory, Department of Immunology, Genetics and Pathology, Uppsala University Hospital, Uppsala, Sweden
Pancreas transplantation is the treatment of choice for patients whose pancreas does not make enough, or sometimes any, insulin. These patients suffer type 1 diabetes, or insulin-dependent type 2 diabetes. A relatively new and minimally invasive therapy is transplantation of the islets of Langerhans [1, 2]. Islets are delivered into the liver by injection to the portal vein, where they produce insulin. Pancreas or islets transplantation is currently the only treatment that restores normal glucose metabolism in insulin-dependent patients [3, 4].

The pancreas is regarded as one of the most challenging donor organs for recovery and transplantation. The selection of deceased donors for pancreas procurement is the key factor of outcome in transplantation of the whole organ or islets. The ideal donor developed brain death as a result of trauma, ranges in age from 10 to 40 years and has a body mass index (BMI) less than $27.5 \mathrm{~kg} / \mathrm{m}^{2}$ [5]. Such strict donor selection has not only resulted in outstanding graft survival but also in underutilization of pancreas donors [6]. Fortunately, recent successes in pancreas transplantation have led to the utilization of less-than-ideal donors. It was demonstrated that graft survival was not significantly different in patients receiving transplants from obese, non-heart beating 
or younger donors compared with grafts from ideal donors $[5,6]$. However, the use of less-than-ideal donors requires methods for an objective assessment of pancreas graft quality. The aim of such methods is to predict either pancreas donor utilization or graft failure. Possible methods of choice are phosphorus $\left({ }^{31} \mathrm{P}\right)[7,8]$ and proton magnetic resonance spectroscopy $\left({ }^{1} \mathrm{H}-\mathrm{MRS}\right)[9-12]$.

${ }^{1} \mathrm{H}-\mathrm{MRS}$ is a promising tool for non-invasive quantification of pancreatic fat content. Fat assessment is an important issue because fatty pancreas is more difficult to procure, and prepare on backbench. In addition, excessive fatty infiltration is associated with an increased risk of complications after pancreatic surgery [5]. BMI seems to be a less reliable measure of pancreas fat content $[9,13]$. Some overweight donors may have little or no fatty infiltration of the pancreas, while some donors with normal BMI may have increased fat content [5, 10, 14]. Excessive alcohol abuse may also increase pancreatic lipid content, even in the absence of obesity $[5,10]$.

Relatively few in vivo ${ }^{1} \mathrm{H}$-MRS studies of human pancreas have been performed [9-12] so far. Lipids and total choline (tCho, free choline, phosphocholine, and glycerophosphocholine) were quantifiable despite experimental difficulties with respiratory motion. It was shown that pancreatic fat content was increased in men with type 2 diabetes $[9,10,15]$. In non-diabetic men the fat content was inversely associated with various indicators for $\beta$-cells functions [9, 14]. It should be noted that ${ }^{1} \mathrm{H}-\mathrm{MRS}$ is able to distinguish between lipids in fat cells (adipocytes) and lipids in nonadipose cells (triglyceride droplets in the cytosol). Examples are intramyocellular [16], intrahepatic [17], intramyocardial lipids [18], and intracellular lipids of non-adipose pancreatic cells (NAPC).
In the present study, we applied ${ }^{1} \mathrm{H}-\mathrm{MRS}$ to human pancreas grafts during cold preservation. First, we measured pancreatic water and fat relaxation times $T_{1}$ and $T_{2}$. Second, knowledge of the relaxation times enabled us to estimate the absolute total fat concentration and intracellular lipids of NAPC. Third, we evaluated the relationship between pancreatic total fat content and donor's BMI.

\section{Materials and methods}

\section{Donors}

Pancreas grafts from 11 human donors were included in this study. Donor's characteristics are shown in Table 1. Organ donation was performed solely for research purposes and was approved by the relatives. We note that the grafts of donors were considered unsuitable for organ transplantation due to the advanced age (nine grafts) or for other reasons (two grafts). The study was approved by the Regional Ethical Review Board in Uppsala. Ten pancreas grafts were perfused in situ with histidine-tryptophan-ketoglutarate (HTK) solution and one graft was perfused with University of Wisconsin (UW) solution. After the perfusion, the pancreata was stored in a plastic container (MEDCO AS, Årvollskogen, Norway) filled with HTK or UW solution. The temperature inside the container was maintained at $4 \pm 2{ }^{\circ} \mathrm{C}$ during the transport to our hospital and MR scanning.

\section{Data acquisition}

Experiments were performed on a Philips Achieva $1.5 \mathrm{~T}$ MR scanner (Philips Healthcare, Best, The Netherlands).
Table 1 Gender, age, BMI of the donors and lipid concentrations of pancreas grafts

\begin{tabular}{|c|c|c|c|c|c|c|c|}
\hline \multirow[t]{3}{*}{ Donor nr } & \multirow[t]{3}{*}{ Gender } & \multirow[t]{3}{*}{ Age (years) } & \multirow[t]{3}{*}{ BMI $\left(\mathrm{kg} / \mathrm{m}^{2}\right)$} & \multicolumn{4}{|c|}{ Concentration } \\
\hline & & & & \multicolumn{2}{|c|}{ Total lipid content } & \multicolumn{2}{|c|}{$\begin{array}{l}\text { Intracellular lipids of } \\
\text { NAPC }\end{array}$} \\
\hline & & & & f/w $(\%)$ & $\mathrm{mmol} / \mathrm{kg} \mathrm{ww}$ & f/w $(\%)$ & $\mathrm{mmol} / \mathrm{kg} \mathrm{ww}$ \\
\hline 1 & M & 56 & 29.2 & 26.61 & 304.38 & - & - \\
\hline 2 & $\mathrm{~F}$ & 62 & 29.4 & 0.83 & 9.53 & 0.36 & 4.07 \\
\hline 3 & M & 24 & 31.9 & 0.21 & 2.4 & 0.12 & 1.36 \\
\hline 4 & M & 68 & 24 & 0.89 & 10.17 & 0.32 & 3.68 \\
\hline 5 & $\mathrm{~F}$ & 63 & 30.9 & 2.78 & 31.8 & - & - \\
\hline 6 & M & 28 & 24.5 & 7.77 & 88.93 & - & - \\
\hline 7 & M & 79 & 22.2 & 5.49 & 62.77 & - & - \\
\hline 8 & $\mathrm{~F}$ & 70 & 23 & 0.38 & 4.34 & 0.21 & 2.38 \\
\hline 9 & $\mathrm{~F}$ & 82 & 31.3 & 4.71 & 53.85 & - & - \\
\hline 10 & M & 70 & 23 & 21.06 & 240.97 & - & - \\
\hline 11 & M & 50 & 22.3 & 5.48 & 62.55 & - & - \\
\hline Mean & & 59.3 & 26.5 & 6.93 & 79.24 & 0.25 & 2.87 \\
\hline
\end{tabular}

$N A P C$ non-adipose pancreatic cells, $f / w$ fat/water spectral intensity ratio 
${ }^{1} \mathrm{H}$-MRS was performed using the standard transmit-receiver quadrature head coil. $T_{2}$-weighted images were applied for voxel positioning. The voxel was placed within the body of the pancreas (Fig. 1). Voxel size was between $10 \times 10 \times 15$ and $10 \times 10 \times 25 \mathrm{~mm}^{3}$. Proton spectra of HTK and UW solutions as well as spectra determined for lipid quantitation were acquired by point-resolved spectroscopy (PRESS) sequence (time repetition TR $5000 \mathrm{~ms}$, time echo TE $30 \mathrm{~ms}$, spectral bandwidth $1000 \mathrm{~Hz}, 1024$ points, 16 phase cycle steps). Two dummy excitations were followed by 16 non-water-suppressed and 64 water-suppressed scans. Net acquisition time was 6 min and $50 \mathrm{~s}$.

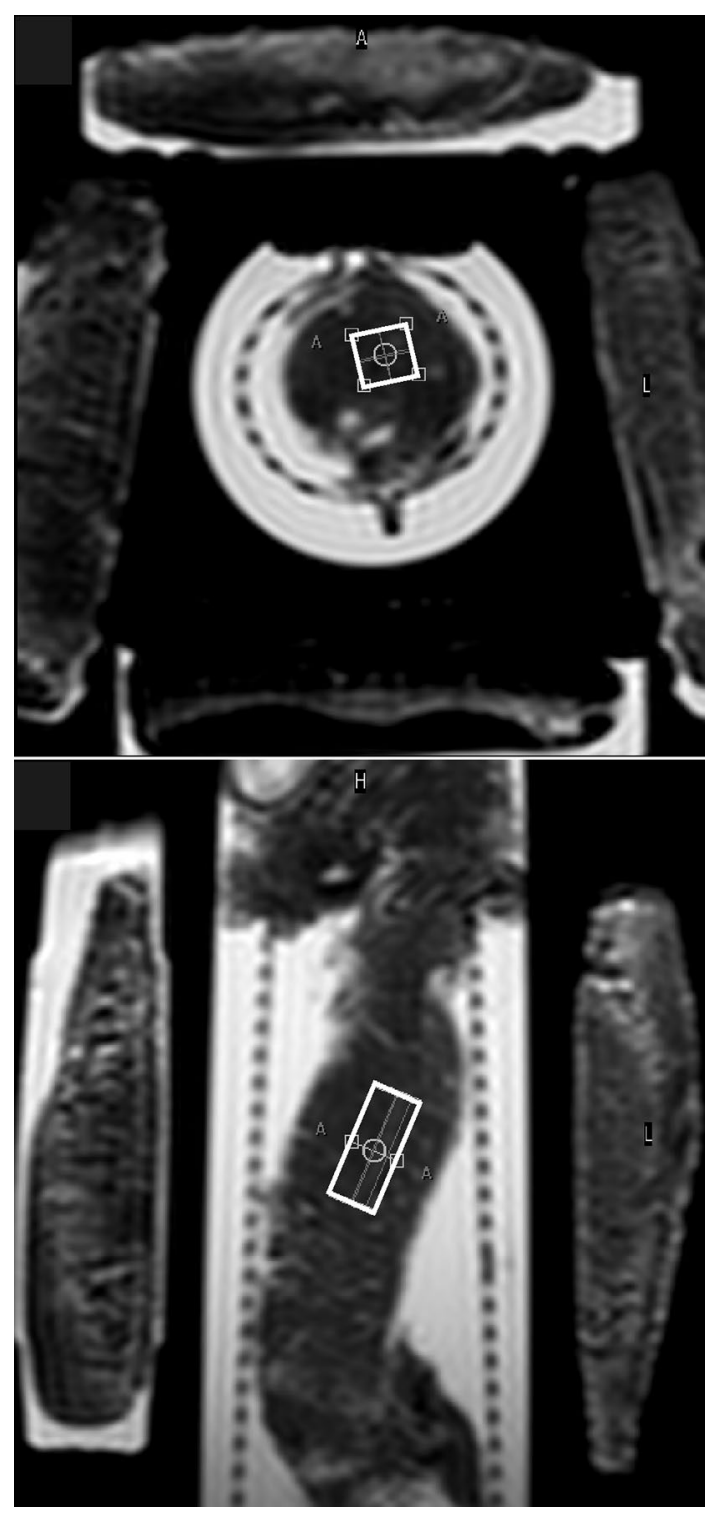

Fig. $1 T_{2}$-weighted MR images showing typical voxel position in the body of the pancreas. Cylindrical transport container was surrounded by four cooling (ice) elements
Water relaxation times $T_{1}$ and $T_{2}$ were computed using the PRESS spectra acquired at ten TRs $(300,350,400,500$, $750,1000,1500,2000,3000,5000 \mathrm{~ms}$, number of scans (NS) 16, TE $30 \mathrm{~ms})$, and eight TEs (30, 40, 50, 75, 100, 125, 150, $200 \mathrm{~ms}$, TR $3000 \mathrm{~ms}$, NS 16). The $T_{1}$ values of lipid $\left(-\mathrm{CH}_{2}-\right)_{\mathrm{n}}$ line was quantified from the spectra measured at TE $25 \mathrm{~ms}$ and TRs 550, 650, 750, 850, 1000, 1200, 1400, and $1600 \mathrm{~ms}$ (NS 64 or 128). The $T_{2}$ value was estimated using the spectra measured at TEs $30,40,50,60,80,100$, 120, and $150 \mathrm{~ms}$ (TR $1500 \mathrm{~ms}$, NS 64 or 128).

The pancreas was measured in its original cylindrical transport container. During scanning hypothermic storage was maintained by three or four cooling elements (Fig. 1). Temperature stability $\left(4 \pm 2{ }^{\circ} \mathrm{C}\right)$ was checked in five grafts by measuring the temperature of the HTK or UW solution inside the transport container just before and immediately after MR examination.

\section{Spectrum processing}

${ }^{1} \mathrm{H}$ spectra were fitted in time domain using AMARES algorithm [19] as implemented in the magnetic resonance user interface (MRUI) software package [20]. After manual phase correction, the residual water line was removed with Hankel-Lanczos singular values decomposition (HLSVD) filter. Spectral lines were fitted with AMARES to Lorentzian line shapes. No apodization of free induction decay was used in this study. Prior knowledge applied for fitting the lipid signals originated from adipocytes and intracellular lipids of NAPC has been described elsewhere [21]. Spectral line at $3.2 \mathrm{ppm}$ (tCho and histidine lines of HTK solution) was fitted by single Lorentzian. Spectral intensities between 3.5 and $4.2 \mathrm{ppm}$ were empirically fitted by three Lorentzians (Fig. 2).

Relaxation times $T_{1}$ and $T_{2}$ were estimated by monoexponential fitting of the spectral intensities (Fig. 3) by a Levenberg-Marquadt algorithm using the commercial software package ORIGIN v. 8.6 (OriginLab, Northampton, MA, USA). Spectral intensities versus TE or TR were fitted using the PRESS relaxation attenuation function $\operatorname{att}\left(T_{1}, T_{2}\right)=\mathrm{ex}$ $\mathrm{p}\left(-\mathrm{TE} / T_{2}\right) \times\left[1-\exp \left(-\mathrm{TR} / T_{1}\right)\right]$.

Lipid content was computed from the relaxation-corrected spectral intensity ratios to unsuppressed water line [22, 23]. Reference concentration $38300 \mathrm{mM}$ of "NMRvisible" water was used in the estimation of the absolute concentration. The value $38300 \mathrm{mM}$ was computed using the assumption that pancreas contains $0.71 \mathrm{~g} \mathrm{H}_{2} \mathrm{O}$ per $1 \mathrm{~g}$ wet weight tissue [12] and its density is $1.08 \mathrm{~g} / \mathrm{cm}^{3}$ [24]. Furthermore, it was assumed that $10 \%$ of tissue water is "NMR-invisible" because of macromolecular binding and other interactions [25]. Lipid content was quantified using methylene intensities. Division by factor 31 was used to 


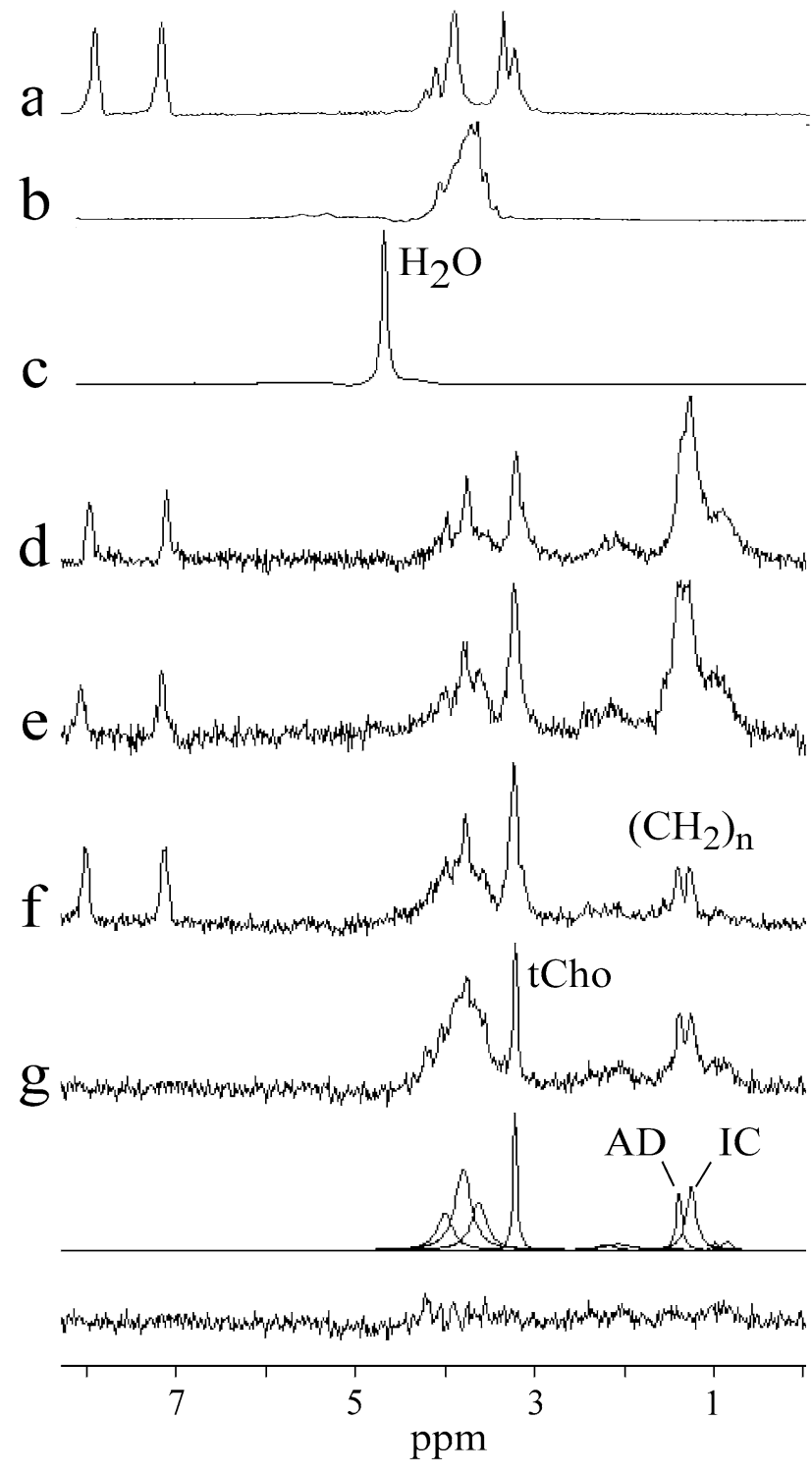

Fig. 2 a ${ }^{1} \mathrm{H}$ spectrum of HTK solution (histidine). b Spectrum of UW solution (raffinose). c-f Spectra of pancreas grafts perfused with HTK solution. c Unsuppressed water line (concentration reference) of spectrum d. g Spectrum of pancreas graft perfused with UW solution, fits and residue. Resonance at $1.3 \mathrm{ppm}$ represents intracellular (IC) lipid methylene line of NAPC. Methylene peak at $1.42 \mathrm{ppm}$ originates from pancreatic adipocytes (AD)

convert methylene concentration to molecular concentration. The value 31 follows from the assumption that the average number of $\left(-\mathrm{CH}_{2}-\right)_{\mathrm{n}}$ groups is 31 per fat (triglyceride) molecule [23]. Division by the pancreas density was used to convert $\mathrm{mM}$ to millimoles per $\mathrm{kg}$ wet weight (mmol/kg ww). Total lipid content was also expressed as the ratio of lipid $\left(-\mathrm{CH}_{2}-\right)_{\mathrm{n}}$ over water spectral intensity $(\mathrm{f} / \mathrm{w})$ for completeness and in line with the previous studies $[9,10]$.
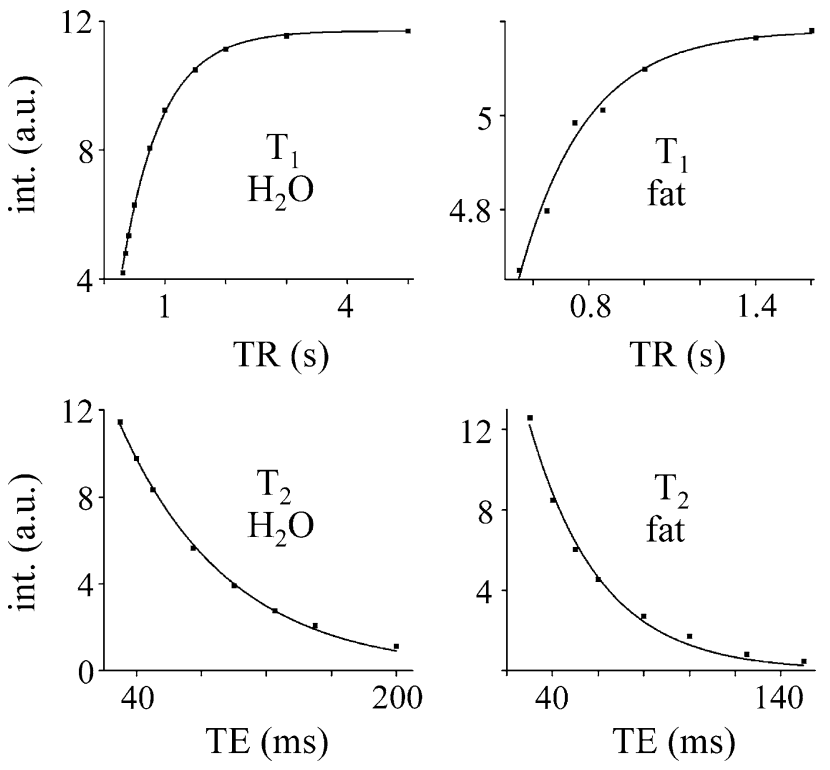

Fig. 3 Monoexponential fits of spectral intensities vs. TR and TE

\section{Statistics}

Quantitative results are presented as means $\pm 1 \mathrm{SD}$. Adjusted coefficient of determination adj. $R^{2}$ was used to express goodness of nonlinear fits. Linear regression was performed to evaluate the relationship between BMI and pancreatic total fat content.

\section{Results}

The pancreas grafts were delivered to our hospital between 5.5 and $12.5 \mathrm{~h}$ (median $8 \mathrm{~h}$ ) after the start of perfusion with HTK or UW solution. All the spectroscopic experiments were performed within a few hours after delivery. Figure 2a, b shows the spectra of HTK and UW solutions, respectively. Only the spectral lines of the HTK's histidine $(180 \mathrm{mM})$ and the UW's raffinose $(30 \mathrm{mM})$ are detectable. Figure $2 \mathrm{c}$ depicts the unsuppressed water line (concentration reference) of spectrum shown in Fig. 2d. Methylene $(-\mathrm{CH} 2-)_{\mathrm{n}}$ spectral lines of intracellular lipids were quantifiable in four spectra (Fig. 2d-g) with low total lipid content ( $\mathrm{f} / \mathrm{w} \leq 0.9 \%)$. The intracellular methylene resonance was unresolvable from methylene peak of pancreatic adipocytes in spectra with increased fat content (not shown). Figure $2 d-f$ show the pancreas spectra perfused by HTK solution. The spectrum of pancreas perfused by UW solution is shown in Fig. $2 \mathrm{~g}$. This spectrum is completed by fits and residue. Resonance at $1.3 \mathrm{ppm}$ represents intracellular (IC) lipid methylene line of NAPC. Methylene peak at $1.42 \mathrm{ppm}$ originates from pancreatic adipocytes (AD). From Fig. $2 \mathrm{~d}-\mathrm{f}$ follows that tCho $(3.2 \mathrm{ppm})$ is 
Table 2 Average $T_{1}$ and $T_{2}$ relaxation times (ms) of normal pancreas grafts at $4 \pm 2{ }^{\circ} \mathrm{C}$

\begin{tabular}{lcc}
\hline & Water $(N=5)$ & Fat $\left(\mathrm{CH}_{2}\right)_{\mathrm{n}}(N=5)$ \\
\hline$T_{1}$ & $670 \pm 69$ & $287 \pm 60$ \\
$T_{2}$ & $77 \pm 17$ & $27 \pm 4$ \\
\hline
\end{tabular}

$N$ number of grafts

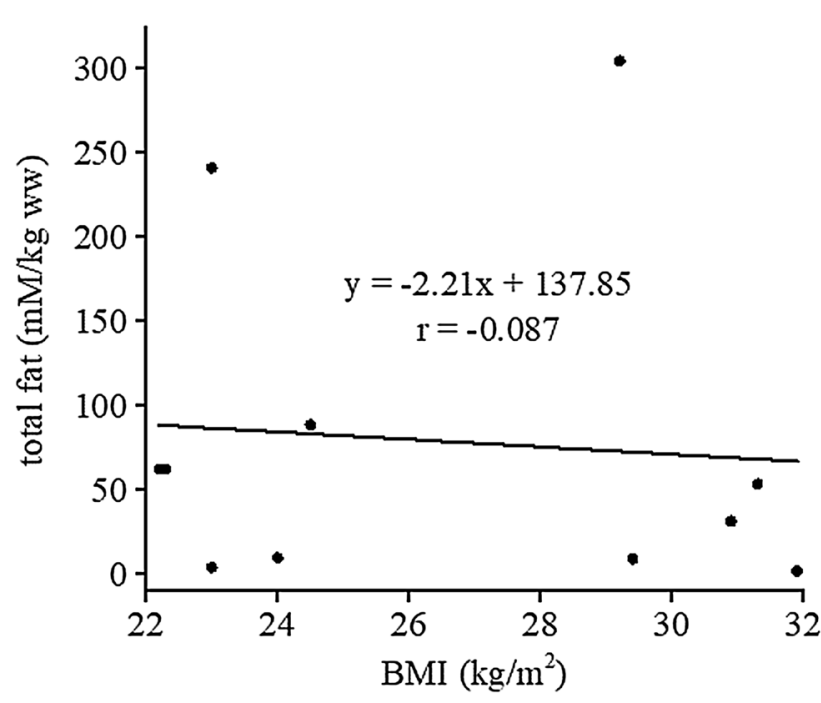

Fig. 4 Scatter plot and regression line illustrating relationship between BMI and total pancreatic lipid content

overlapped by strong signals of histidine doublet of doublets. In contrast, tCho is clearly separated from neighboring resonances in Fig. 2g. The intensities between 3.4 and $4.2 \mathrm{ppm}$ were fitted by three Lorentzians. These fits refer to an empirical attempt to compensate for the signals in this region containing a large number of spectral lines with a high degree of overlap. Histidine (HTK solution) and raffinose (UW solution) dominate in this spectral interval. However, glucose, glycerol, choline, phosphocholine, glycerophosphocholine, myo-Inositol, ethanolamine, uridine, and amino acids were also identified in this region using high-resolution magic angle spinning (HR-MAS) spectroscopy [26].

Excellent match of spectral intensities to monoexponential functions was achieved for water relaxation times $T_{1}$, $T_{2}$ (adjusted $R^{2} \geq 0.991$ ). Adjusted $R^{2}$ between 0.846 and 0.984 was achieved for fat $T_{1}$. Spin-spin relaxation time $T_{2}$ of the lipid methylene spectra line was fitted within the interval $0.985 \leq$ adj. $R^{2} \leq 0.992$. Relaxation times are summarized in Table 2. Concentrations of total fat and intracellular lipids of NAPC are shown in Table 1. No correlation $(r=-0.087)$ was found between total fat content and BMI (Fig. 4).

\section{Discussion}

To our knowledge, this is the first ${ }^{1} \mathrm{H}$-MRS study of human pancreas grafts. For the first time relaxation times were measured during the cold preservation $\left(\sim 4{ }^{\circ} \mathrm{C}\right)$ and for the first time intracellular lipids of non-adipose pancreatic cells were detected and quantified by ${ }^{1} \mathrm{H}$-MRS.

In vivo quantitation of intracellular lipids of NAPC is a difficult task. Navigator-guided acquisition, respiratory triggering, or measurement during breath-hold are able to suppress spectral distortions, however, remaining residual respiratory, peristaltic and heart motion could cause additional phase and frequency distortions and anomalies in water suppression [27]. Spectroscopy of the pancreas grafts during cold storage offer the unique opportunity to obtain spectra free from motion artifacts. However, the absolute quantitation of intracellular lipids of NAPC is not always possible in spite of motion artifact-free spectra. Quantification depends on the ability of fitting algorithm to distinguish methylene spectral line of intracellular lipids at $1.3 \mathrm{ppm}$ from the methylene line of adipocytes at $\sim 1.4 \mathrm{ppm}$. Already modest increase of pancreatic adipocytes produces dominant lipid $\left(-\mathrm{CH}_{2}-\right)_{\mathrm{n}}$ signal which contaminate the intracellular spectral line due to severe overlap. Intracellular lipids are then indistinguishable. Increased spectral resolution at higher magnetic fields $\left(B_{0} \geq 7 \mathrm{~T}\right)$ can substantially improve detectability of intracellular lipids. Total Cho peak at $3.2 \mathrm{ppm}$ is also undetectable when the lipid peak is high.

In vivo estimation of pancreatic water relaxation times $T_{1}\left(584 \pm 14 \mathrm{~ms}\right.$ and $T_{2}(46 \pm 6 \mathrm{~ms})$ was published by de Bazelaire et al. [28]. Our shorter $T_{1}$ and longer $T_{2}$ values can be explained by the fact that the pancreatic blood was replaced by HTK or UW solution. Measured $T_{1}$ relaxation time of lipid $\left(-\mathrm{CH}_{2}-\right)_{\mathrm{n}}$ peak is shorter, about $\sim 70 \mathrm{~ms}$, and $T_{2}$ is by factor $\sim 2$ smaller compared to the reported in vivo values of subcutaneous fat $[28,29]$. This phenomenon can be explained by the low temperature during the experiments $\left(4 \pm 2{ }^{\circ} \mathrm{C}\right)$. Baron et al. [30] reported that $T_{1}$ temperature $(T)$ dependence of female breast adipose tissue can be described by the function $A \times \exp [-B /$ $(T+273.15)]$ where $A$ and $B$ are constants. $T_{1}$ temperature coefficient decreased from $\mathrm{d} T_{1} / \mathrm{d} T=9.5 \pm 0.16 \mathrm{~ms} /{ }^{\circ} \mathrm{C}$ to $5.35 \pm 0.08 \mathrm{~ms} /{ }^{\circ} \mathrm{C}$ in the interval from 65 to $25^{\circ} \mathrm{C}$. Linear dependence $\left(0.9 \pm 0.03 \mathrm{~ms} /{ }^{\circ} \mathrm{C}\right)$ was found between $T_{2}$ and temperature. These $T_{1}, T_{2}$ dependences and the temperature difference $\sim 33{ }^{\circ} \mathrm{C}$ between in vivo and cold storage explain the shorter relaxation times.

In this study, we found the pancreatic fat content ( $\mathrm{f} / \mathrm{w}$ ) to be very similar, to those reported for healthy subjects $[9,10,12,13]$. Spectroscopic voxel was placed within the body of the pancreas (Fig. 1) because of the need for 
large voxel size and because no significant [31] or small [15] difference of the fat content was reported between the head, body, and tail. No correlation was found between fat content and BMI. This result is in agreement with the previous studies of Tushuizen and Gaborit et al. [9, 13]. However, Lingvay et al. [10] and Kühn et al. [15] found a positive association of pancreatic fat content with BMI.

Pancreatic intracellular lipid accumulation is currently of considerable interest. It was shown that an increased content of cytosolic lipid droplets in islets of Langerhans leads to decreased glucose-stimulated insulin secretion $[32,33]$. This phenomenon has been called as $\beta$-cell lipotoxicity [34]. To our knowledge, there are no previous estimates of human pancreatic intracellular lipids of NAPC that can be compared with our results. The intracellular lipid content we found is comparable with intramyocellular lipids of the calf muscles [21, 35, 36]. It is important to note that ${ }^{1} \mathrm{H}$-MRS is unable to discriminate between intracellular lipids of acinar and the islet of Langerhans cells.

The main limitation of this study is the small number of grafts and age of donors. It should be noted that the grafts were considered unsuitable for transplantation mainly due to advanced age. A further limitation is the fact that increased pancreatic fat content hinders detection of intracellular lipids of NAPC. The usability of the measured relaxation times is limited to the grafts perfused by HTK or UW solution and to the temperature of cold storage $\left(4 \pm 2{ }^{\circ} \mathrm{C}\right)$.

\section{Conclusions}

The present results suggest that ${ }^{1} \mathrm{H}-\mathrm{MRS}$ is a useful tool for quantification of pancreas graft lipid concentrations using water as the internal concentration reference. Total pancreatic fat and especially content of intracellular lipids of NAPC are valuable measures for inspection of graft quality prior to transplantation or islet of Langerhans isolation.

Acknowledgements This work was supported by the Swedish Research Council (VR K2013-64X-08268-26-3, 921-2014-7054 (KBF), K201554X-12219-19-4), the Nordic Insulin Fund, the Diabetes Wellness foundation, the Ernfors Family Fund, Barn Diabetes Fonden, the Swedish Diabetes Association and the Juvenile Diabetes Foundation International (17-2012-540). Human pancreases were obtained from The Nordic network for Clinical islet Transplantation, supported by the Swedish national strategic research initiative EXODIAB (Excellence of Diabetes Research in Sweden) and the Juvenile Diabetes Research Foundation.

Author contributions Protocol/project development: OK, JW, HA. Acquisition of data: JW. Analysis and interpretation of data: JW, OK, HA.

\section{Compliance with ethical standards}

Conflict of interest The authors declare they have no conflict of interest.

Ethical approval The study was approved by the local ethics committee.

Informed consent Organ donation was approved by the relatives.

Open Access This article is distributed under the terms of the Creative Commons Attribution 4.0 International License (http://creativeco mmons.org/licenses/by/4.0/), which permits unrestricted use, distribution, and reproduction in any medium, provided you give appropriate credit to the original author(s) and the source, provide a link to the Creative Commons license, and indicate if changes were made.

\section{References}

1. Wahoff DC, Papalois BE, Najarian JS et al (1995) Autologous islet transplantation to prevent diabetes after pancreatic resection. Ann Surg 222:562-579

2. Shapiro JAM, Lakey JRT, Ryan EA et al (2000) Islet transplantation in seven patients with type 1 diabetes mellitus using a glucocorticoid-free immunosuppressive regimen. N Engl J Med 343:230-238

3. Gruessner RWG, Sutherland DER, Gruessner AC (2004) Mortality assessment for pancreas transplants. Am J Transplant 4:2018-2026

4. White SA, Shaw JA, Sutherland DER (2009) Pancreas transplantation. Lancet 373:1808-1817

5. Fridell JA, Rogers J, Stratta RJ (2010) The pancreas allograft donor: current status, controversies, and challenges for future. Clin Transplant 24:433-449

6. Krieger NR, Odorico JS, Heisey DM et al (2003) Underutilization of pancreas donors. Transplantation 75:1271-1276

7. Carlbom L, Weis J, Johansson L, Korsgren O, Ahlström H (2017) Pre-transplantation 31P-magnetic resonance spectroscopy for quality assessment of human pancreatic grafts-a feasibility study. Magn Reson Imag 39:98-102

8. Scott WE, Weegman BP, Ferrer-Fabrega J et al (2010) Pancreas oxygen persufflation increases ATP levels as shown by nuclear magnetic resonance. Transplant Proc 42:2011-2015

9. Tushuizen ME, Bunck MC, Pouwels PJ et al (2007) Pancreatic fat content and $\beta$-cell function in men with and without type 2 diabetes. Diabetes Care 30:2916-2921

10. Lingvay I, Esser V, Legendre JL et al (2009) Noninvasive quantification of pancreatic fat content in humans. J Clin Endocrinol Metab 94:4070-4076

11. Su TH, Jin EH, Shen H, Zhang Y, He W (2012) In vivo proton MRS of normal pancreas metabolites during breath-holding and free-breathing. Clin Radiol 67:633-637

12. Ouwerkerk R, Gharib AM (2012) ${ }^{1} \mathrm{H}-\mathrm{MRS}$ of pancreatic metabolites. In: Proceedings of the 20th scientific meeting, International Society for Magnetic Resonance in Medicine, Melbourne, p 1373

13. Gaborit B, Abdesselam I, Kober F et al (2015) Ectopic fat storage in the pancreas using ${ }^{1} \mathrm{H}$-MRS: importance of diabetic status and modulation with bariatric surgery-induced weight loss. Int J Obesity 39:480-487

14. Heni M, Machann J, Steiger H et al (2010) Pancreatic fat content is negatively associated with insulin secretion in individuals 
with impaired fasting glucose and/or impaired glucose tolerance: a nuclear magnetic resonance study. Diabetes Metab Res Rev 26:200-205

15. Kühn J-P, Berthold F, Mayerle J et al (2015) Pancreatic steatosis demonstrated at MR imaging in the general population: clinical relevance. Radiology 276:129-136

16. Boesch C (2007) Musculoskeletal spectroscopy. J Magn Reson Imag 25:321-338

17. Szczepaniak LS, Nurenberg P, Leonard D et al (2005) Magnetic resonance spectroscopy to measure hepatic triglyceride content: prevalence of hepatic steatosis in the general population. Am J Physiol Endocrinol Metab 288:E462-E468

18. Szczepaniak LS, Dobbins RL, Metzger GJ et al (2003) Myocardial triglycerides and systolic function in humans: in vivo evaluation by localized proton spectroscopy and cardiac imaging. Magn Reson Med 49:417-423

19. Vanhamme L, van den Boogaart A, Van Huffel S (1997) Improved method for accurate and efficient quantification of MRS data with use of prior knowledge. J Magn Reson 129:35-43

20. Naressi A, Couturier C, Devos JM et al (2001) Java-based graphical user interface for the MRUI quantitation package. MAGMA $12: 141-152$

21. Weis J, Johansson L, Ortiz-Nieto F, Ahlström H (2009) Assessment of lipids in skeletal muscle by LCModel and AMARES. J Magn Reson Imag 30:1124-1129

22. Barker PB, Soher BJ, Blackband SJ, Chatham JC, Mathews VP, Bryan RN (1993) Quantification of proton NMR spectra of the human brain using tissue water as an internal concentration reference. NMR Biomed 6:89-94

23. Boesch C, Machann J, Vermathen P, Schick F (2006) Role of proton MR for the study of muscle lipid metabolism. NMR Biomed 19:968-988

24. Eckhard M, Brendel MD, Brandhorst D, Brandhorst H, Bretzel RG (2004) Can the density of native pancreatic tissue slices predict human islet isolation and purification outcome? Transplant Proc $36: 2845-2848$

25. Heerschap A, Jager GJ, Van der Graaf M, Barentsz JO, Ruijs SH (1997) Proton MR spectroscopy of the normal human prostate with an endorectal coil and a double spin-echo pulse sequence. Magn Reson Med 37:204-213

26. Misra D, Gupta V, Sonkar AA, Bajpai U, Roy R (2008) Proton HR-MAS NMR spectroscopic characterization of metabolites in various human organ tissues: pancreas, brain and liver from trauma cases. Physiol Chem Phys Med NMR 40:67-88

27. Weis J, Kullberg J, Ahlström H (2018) Multiple breath-hold proton spectroscopy of human liver at $3 \mathrm{~T}$ : relaxation times and concentration of glycogen, choline, and lipids. J Magn Reson Imag 47:410-417

28. De Bazelaire CMJ, Duhamel GD, Rofsky NM, Alsop DC (2004) MR imaging relaxation time of abdominal and pelvic tissues measured in vivo at $3.0 \mathrm{~T}$ : preliminary results. Radiology 230:652-659

29. Rakow-Penner R, Daniel B, Yu H, Sawyer-Glover A, Glover GH (2006) Relaxation times of breast tissue at $1.5 \mathrm{~T}$ and $3 \mathrm{~T}$ measured using IDEAL. J Magn Reson Imag 23:87-91

30. Baron P, Deckers R, Knuttel FM, Bartels LW (2015) $\mathrm{T}_{1}$ and $\mathrm{T}_{2}$ temperature dependence of female human breast adipose tissue at $1.5 \mathrm{~T}$ : groundwork for monitoring thermal therapies in the breast. NMR Biomed 28:1463-1470

31. Livingstone RS, Begovatz P, Kahl S et al (2014) Initial clinical application of modified Dixon with flexible echo times: hepatic and pancreatic fat assessment in comparison with ${ }^{1} \mathrm{H}-\mathrm{MRS}$. Magn Reson Mater Phy 27:397-405

32. Zhou YP, Grill VE (1994) Long-term exposure of rat pancreatic islets to fatty acids inhibits glucose-induced insulin secretion and biosynthesis through a glucose fatty acid cycle. J Clin Invest 93:870-876

33. Schaffer JE (2003) Lipotoxicity: when tissues overeat. Curr Opin Lipidol 14:281-287

34. McGarry JD, Dobbins R (1999) Fatty acids, lipotoxicity and insulin secretion. Diabetologia 42:128-138

35. Hwang JH, Pan JW, Heydari S, Hetherington HP, Stein DT (2001) Regional differences in intramyocellular lipids in humans observed by in vivo ${ }^{1} \mathrm{H}-\mathrm{MR}$ spectroscopic imaging. J Appl Physiol 90:1267-1274

36. Howald H, Boesch C, Kreis R et al (2002) Content of intramyocellular lipids derived by electron microscopy, biochemical assays, and ${ }^{1}$ H-MR spectroscopy. J Appl Physiol 92:2264-2272

Publisher's Note Springer Nature remains neutral with regard to jurisdictional claims in published maps and institutional affiliations. 